\title{
Detection of Burkholderia pseudomallei by SYBR Green Real Time PCR
}

\author{
Keld Andresen, Rimtas Dargis, Michael Kemp* and Jens Jørgen Christensen
}

Department of Bacteriology, Mycology and Parasitology, Statens Serum Institute, Copenhagen, Denmark

\begin{abstract}
Development of rapid and sensitive techniques for detection of $B$. pseudomallei is an important aim for public health. Here we report a $B$. pseudomallei specific SYBR Green-based real time PCR targeting a species specific toxin gene. The assay is able to detect 1-2 genome equivalents of $B$. pseudomallei.
\end{abstract}

Keywords: Melioidosis, Burkholderia pseudomallei, PCR detection.

\section{INTRODUCTION}

The genus Burkholderia comprises more than 20 validly named species. However, only 2 species are frequently encountered as human pathogens, B. pseudomallei and B. cepacia complex. Of these two, $B$. pseudomallei is the most important and is responsible for melioidosis, an infectious disease endemic in Southeast Asia and northern Australia. B. pseudomalle $i$ is one of the most important causes of community-acquired septicemia in north-eastern Thailand and the Northern Territory of Australia. A very high mortality rate is seen in patients with septicemic melioidosis and these patients often deteriorate quickly and death often occurs within a few days after infection [1]. It is therefore evident, that early detection of the bacterium is important in clinical diagnosis. In Denmark, we see an increase in the number of $B$. pseudomallei cases due to travelling to areas, where the bacterium is present. In addition, since the emergence of the bioterror threat, early recognition of a biocrime or bioterrorism event requires rapid and accurate diagnostic methods for detection of $B$. pseudomallei. As melioidosis is a serious disease and B. Pseudomallei should only be cultured under biosafety level-3 (BSL-3) conditions, fast and safe alternatives to identification by culture are clearly warranted.

Several PCR methods have been described for detecting B. pseudomallei. The targets for these methods include $16 \mathrm{~S}$ rRNA, $23 \mathrm{~S}$ rRNA, 16S-23S intergenic region, a repetitive element, type III secretion system genes, flagellin C and ribosomal protein subunit $\mathrm{S} 21$ [2-7]. The aim of this study was to develop and evaluate a SYBR Green-based Real Time PCR that could be implemented in the range of existing assays at the Danish National Centre for Biological Defence (NCBD). We therefore searched for B. pseudomallei specific sequences/genes among the already genome-sequenced Burkholderia species in public databases and after identification of potential sequences we designed appropriate PCR primers and tested them in PCR.

*Address correspondence to this author at the Department of Bacteriology, Mycology and Parasitology, Statens Serum Institute, Artillerivej 5, DK2300 Copenhagen S, Denmark; Tel: +45 3268 3371; Fax: +45 3268 3873; E-mail:MKE@ssi.dk
Table 1. List of Bacterial Strains Used and the Specificity of the PCR Primers

\begin{tabular}{|c|c|c|}
\hline Species $^{a}$ & Strain $^{b}$ & PCR Results with Primers Bps3F/R \\
\hline B. pseudomallei & AB 2056 & + \\
\hline B. pseudomallei & ATCC 15682 & + \\
\hline B. pseudomallei & NCTC 10274 & + \\
\hline B. pseudomallei & NCTC 10276 & + \\
\hline B. pseudomallei & PJ 54 & + \\
\hline B. mallei & $\mathrm{AB} 1715$ & - \\
\hline B. mallei & AB 1716 & - \\
\hline B. cepacia & King 7179 & - \\
\hline B. серасіа & ATCC 17559 & - \\
\hline B. cepacia & D142 & - \\
\hline B. cepacia & U65 & - \\
\hline B. cepacia & AB 2436 & - \\
\hline B. vietnamiensis & 16230 & - \\
\hline R. pickettii & U79 & - \\
\hline S. maltophilia & U61 & - \\
\hline E. coli & ATCC 25922 & - \\
\hline P. aeruginosa & ATCC 27853 & - \\
\hline S. aureus & ATCC 25923 & - \\
\hline E.faecalis & ATCC 29212 & - \\
\hline S. pyogenes & ATCC 51500 & - \\
\hline N. gonorrhoeae & ATCC 49226 & - \\
\hline H. influenzae & $\mathrm{SSI}^{\mathrm{c}}$ & - \\
\hline P. multocida & $\mathrm{SSI}^{\mathrm{c}}$ & - \\
\hline \multicolumn{3}{|c|}{$\begin{array}{l}\text { a'B. pseudomallei: Burkholderia pseudomallei; R. pickettii: Ralstonia pickettii; } S \\
\text { maltophilia: Stenotrophomonas maltophilia; E. col:, Escherichia coli; P. aeruginosa. } \\
\text { Pseudomonas aeruginosa; S. aureus: Staphylococcus aureus; E. faecalis: Enterococ- } \\
\text { cus faecalis; S. pyogenes: Streptococcus pyogenes; N. gonorrhoeae: Neisseria gonor- } \\
\text { rhoeae; H. influenzae: Haemophilus influenzae; } P \text {. multocida: Pasteurella multocida. } \\
{ }^{\circ} \text { ATCC, American Type Culture Collection, Manassas, Va.; NCTC, National Collec- } \\
\text { tion of Type Cultures, Central Public Health Laboratory, London, England. } \\
\text { 'Clinical isolates identified by standard phenotypic characteristics at the National Ref- } \\
\text { erence Laboratory for Bacterial Identificaion at Statens Serum Institute, Copenhagen } \\
\text { Denmark. }\end{array}$} \\
\hline
\end{tabular}

2009 Bentham Open 
From several primer pair candidates we designed a PCR targeting a $B$. pseudomallei specific gene sequence BPSL1664, encoding an ATP-binding transport-related membrane protein (GenBank accession no. BX571965 REGION: 1936340..1938640). The ATP-binding cassette systems in B. pseudomallei and B. mallei have been reviewed by Harland et al. [8]. The primers used were Bps3F (5'GGC CAC CGC CCA TTG CCG AGC AAG GAG CAT ATG) and Bps3R (5'- CCG TTC GGC GCT ACC GTG TTG AAG ATG ACC AAT GA) amplifying a $170 \mathrm{bp}$ amplicon. The SYBR Green PCR was performed in $50 \mu 1$ reaction volumes consisting of: $1 \mathrm{x}$ QuantiTect SYBR Green PCR Master Mix (Qiagen, Hilden, Germany) and $20 \mu \mathrm{M}$ each of primer Bps3F and Bps3R. The PCR conditions were as follows: $95^{\circ} \mathrm{C}$ for $15 \mathrm{~min}$, and 50 cycles of $94^{\circ} \mathrm{C}$ for $30 \mathrm{~s}$ and $72^{\circ} \mathrm{C}$ for $60 \mathrm{~s}$ using the MJ Research Opticom Real Time cycler (MJ Research, USA).

We started by evaluating the potential of the PCR to amplify all our B. pseudomallei strains. All the strains evaluated in this study are listed in Table 1. Of the five different strains of B. pseudomallei used in the assay, all gave a positive amplification profile and no amplification was seen from other Burkholderia species (Fig. 1). When the B. pseudomallei PCR amplicons were run on an agarose gel, the expected 170 bp product was identified (data not shown). The amplicon melting temperatures of the five $B$. pseudomallei strains was 85.6 to $86^{\circ} \mathrm{C}$.

To determine the sensitivity of the assay using purified genomic DNA, we made 10-fold dilutions ranging from 0.5 ng and down to $5 \mathrm{fg}$ of template DNA (Fig. 2). The detection limit of the assay was $10 \mathrm{fg}$ of DNA equivalent to $1-2$ genomes of B. pseudomallei as calculated from a total genome size of 7.2 Mbp.

To evaluate the specificity of the assay, genomic DNA was extracted from a range of different clinical and reference bacterial strains other than Burkholderia spp. (Table 1). Except for the positive control (B. pseudomallei), none of the

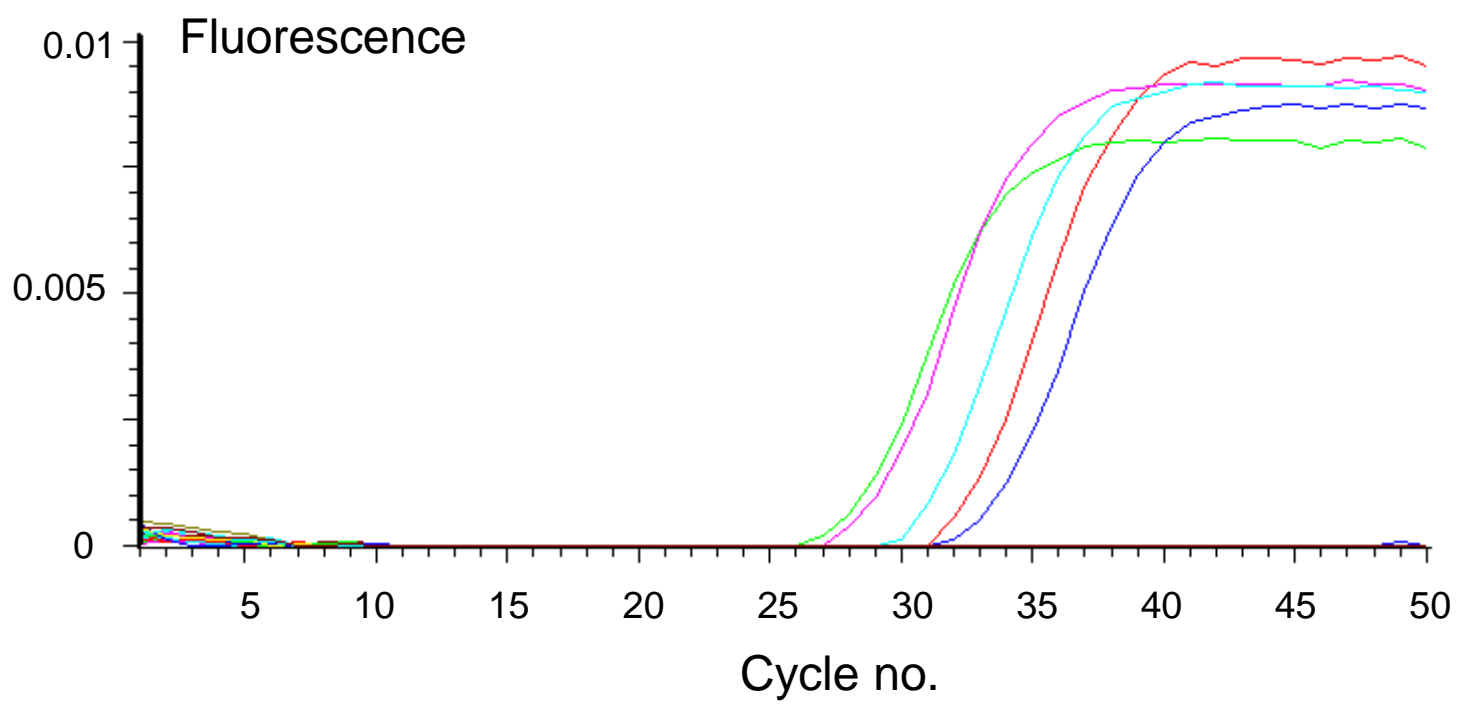

Fig. (1). Specificity of the primers tested on a range of different Burkholderia species consisting of B. pseudomallei, B. mallei, B. cepacia and $B$. vietnamiensis. Only the five different strains of $B$. pseudomallei used give a positive amplification.

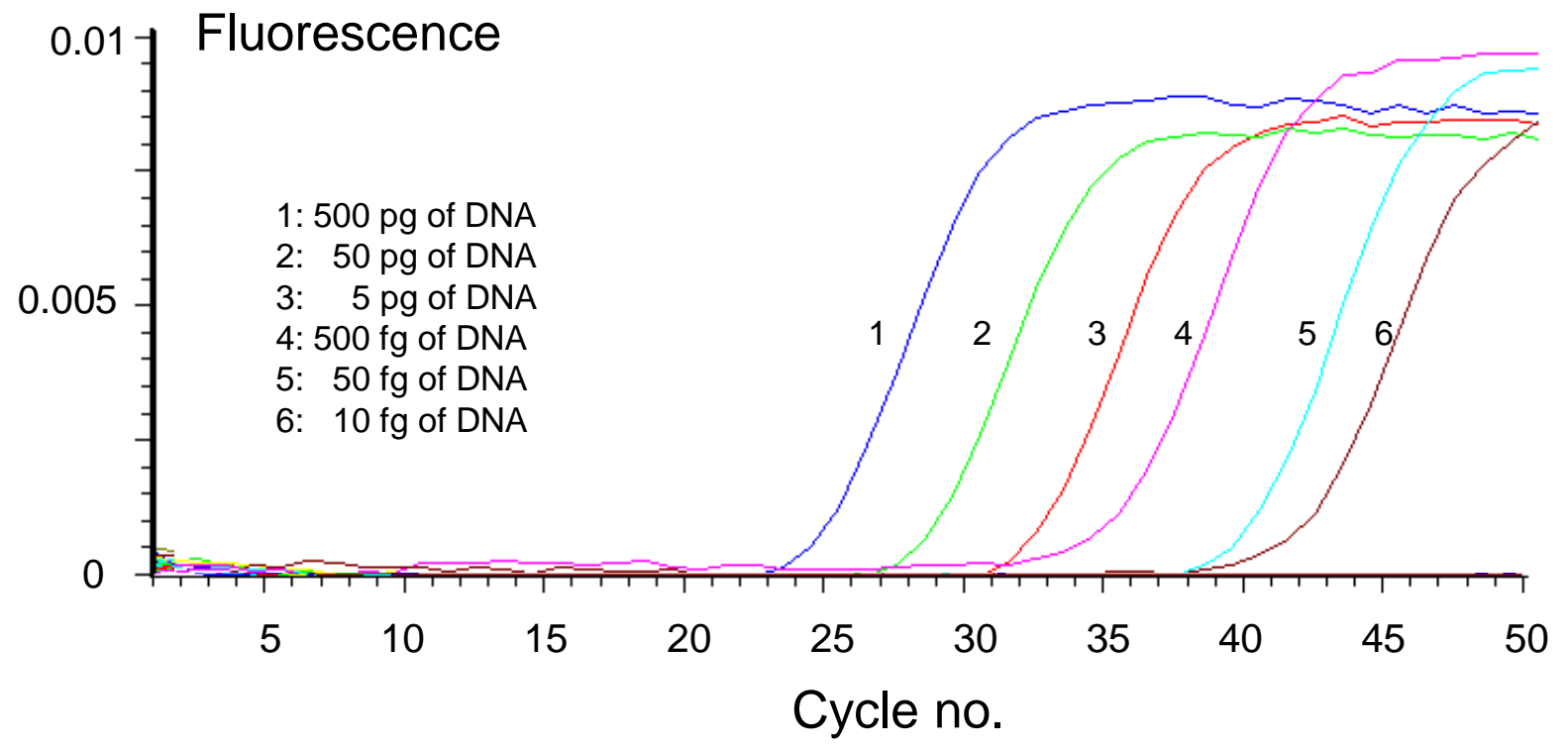

Fig. (2). Amplification curves of different dilutions of B. pseudomallei template ranging from $0.5 \mathrm{ng}$ to $10 \mathrm{fg}$ of DNA. 


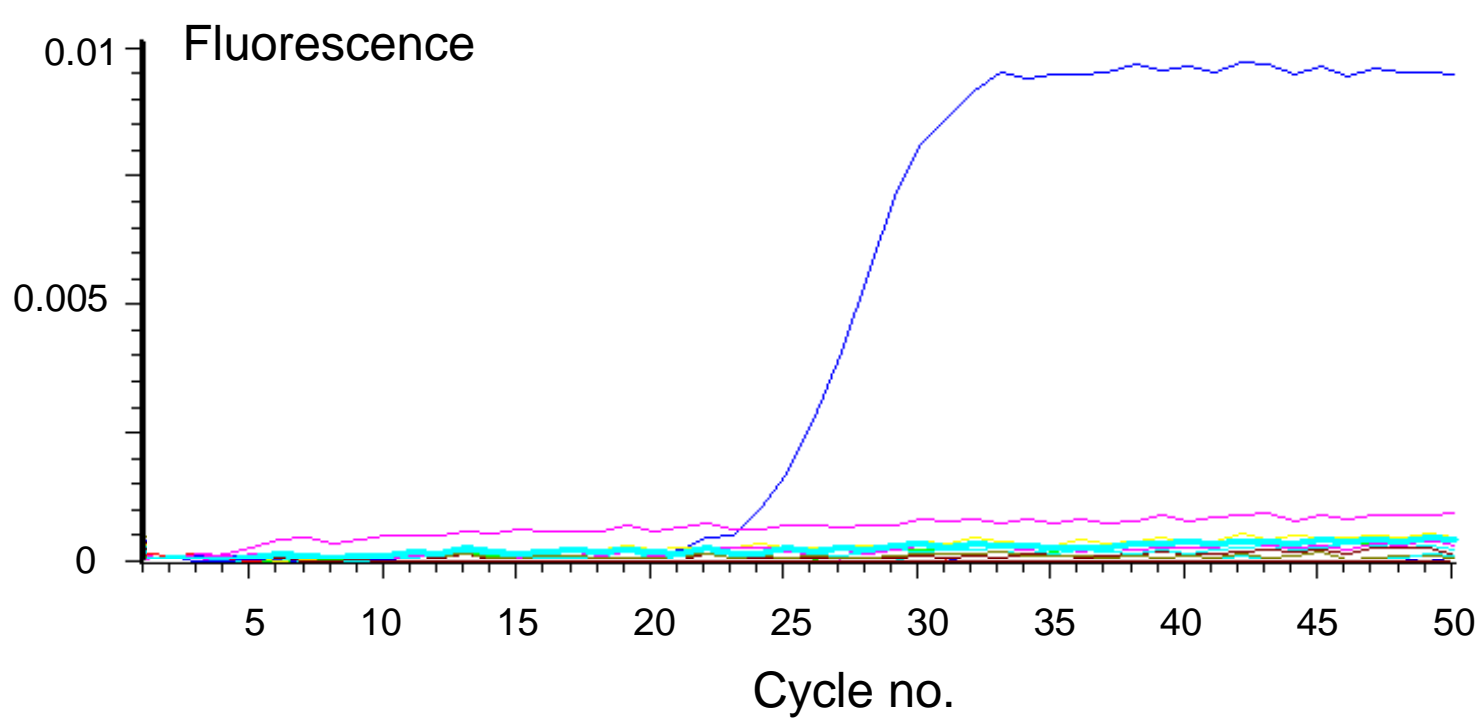

Fig. (3). Specificity of the primers tested on a range of different bacteria other than Burkholderia spp. The bacteria tested are listed in Table 1. Only B. pseudomallei (positive control, $0.5 \mathrm{ng}$ ) gives an amplification product. The other bacteria species do not give amplification above the baseline fluorescence.

other clinical or reference bacterial strains gave any amplification products indication the high degree of specificity of this assay (Fig. 3). This was to be expected as no significant similarity to the selected gene was found in the databases among the other more than 300 full or partly genomesequenced bacteria.

Due to the high degree of specificity of this SYBR Green assay, we have chosen not to develop it further to a TaqMan assay or similar at this point. However, an added benefit of the SYBR Green assay is the melting curve analysis, which can be used as a confirmation of the right amplicon. In order for the assay to be implemented in the range of existing assays at the Danish National Centre for Biological Defence, we are in the progress of testing its robustness using a variety of environmental samples spiked with B. pseudomallei.

Melioidosis is a very severe and potentially lethal disease often requiring long term antibiotic and surgical treatment. Between one and three Danish patients are now diagnosed with melioidosis each year after returning from areas where the disease is endemic, in particular North-eastern parts of Thailand. Danish diagnostic routine laboratories are not prepared for handling highly contagious BSL-3 organisms such as $B$. pseudomallei and there is a clear need for the availability of highly specific analyses in a specialised laboratory. The assay described here offers a fast, safe and specific alternative to culture and phenotypic characterisation for the detection of $B$. pseudomallei in isolates and clinical samples from patients suspected to suffer from melioidosis.

\section{REFERENCES}

[1] Chaowagul W, White NJ, Dance DA, et al. Melioidosis: a major cause of community-acauired septicaemia in northeastern Thailand. J Infect Dis 1989; 159: 890-99.

[2] Dharakul T, Songsivilai S, Viriyachitra S, Luangwedchakarn V, Tassaneetritap B, Chaowagul W. Detection of Burkholderia pseudomallei DNA in patients with septicaemic melioidosis. J Clin Microbiol 1996; 34: 609-14.

[3] Kunakorn M, Markham RB. Clinically practical seminested PCR for Burkholderia pseudomallei quantitated by enzyme immunoassay with and without solution hybridization. J Clin Microbiol 1995; 33: 2131-3215.

[4] Lee MA, Wang D, Yap EH. Detection and differentiation of Burkholderia pseudomallei, Burkholderia mallei and Burkholderia thailandensis by multiplex PCR. FEMS Immunol Med Microbiol 2005; 43: 413-17.

[5] Lew AE, Desmarchelier, PM. Detection of Pseudomonas pseudomallei by PCR and hybridisation. J Clin Microbiol 1994; 32: 1326-32.

[6] Thibault FM, Valade E, Vidal DR. Identification and discrimination of Burkholderia pseudomallei, B. mallei, and B. thailandensis by real-time PCR targeting type III secretion system genes. J Clin Microbiol 2004; 42: 5871-74.

[7] Tomaso H, Pitt TL, Landt O, et al. Rapid presumptive identification of Burkholderia pseudomallei with real-time PCR assays using fluorescent hybridization probes. Mol Cell Probes 2005; 19: 9-20.

[8] Harland DN, Dassa E, Titball RW, Brown KA, Atkins HS. ATPbinding cassette systems in Burkholderia Pseudomallei and Burkholderia mallei. BMC genomics [serial on the Internet] 2007 March 28; 8: (83): [About 15 screens]. Available from: http://www. biome dcentral.com/1471-2164/8/83. 